Georgia State University

ScholarWorks @ Georgia State University

8-14-2009

\title{
Evaluation of a Body Pillow to Aid Pediatric Spinal Fusion Recovery
}

Naomi Eve Joffe

Follow this and additional works at: https://scholarworks.gsu.edu/psych_theses

Part of the Psychology Commons

\section{Recommended Citation}

Joffe, Naomi Eve, "Evaluation of a Body Pillow to Aid Pediatric Spinal Fusion Recovery." Thesis, Georgia State University, 2009.

doi: https://doi.org/10.57709/1061237

This Thesis is brought to you for free and open access by the Department of Psychology at ScholarWorks @ Georgia State University. It has been accepted for inclusion in Psychology Theses by an authorized administrator of ScholarWorks@Georgia State University. For more information, please contact scholarworks@gsu.edu. 


\title{
EVALUATION OF A BODY PILLOW TO AID \\ PEDIATRIC SPINAL FUSION RECOVERY
}

by

\section{NAOMI EVE JOFFE}

Under the Direction of Lindsey L. Cohen, Ph.D.

\begin{abstract}
Spinal fusion is a surgical procedure used to correct structural spinal damage or abnormalities. Recovery is painful and consists of a minimum 3-day hospital stay. Specific body positioning is necessary for healing but is difficult to maintain due to physical discomfort. The purpose of this study was to use a single-subject multiple baseline design to compare the current practice of using standard hospital pillows to a body-sized pillow for increasing comfort and decreasing pain in pediatric patients recovering from spinal fusion surgery. Four adolescents who had recently undergone spinal fusion surgery served as participants. Outcome measures included self- and nurse-report, heart rate, and requested medication. Three patients found that the BodyPillow ${ }^{\circledR}$ increased their comfort as they recovered from surgery; the fourth reported that he
\end{abstract}


was less comfortable. No changes in pain were reported with the BodyPillow®. Results should help guide medical care and future research regarding pediatric spinal fusion recovery.

INDEX WORDS: Pediatric psychology, Medical pain, Spinal fusion surgery, Positioning, Adolescents, Environmental factors, Comfort, Multiple-baseline design 


\title{
EVALUATION OF A BODY PILLOW TO AID \\ PEDIATRIC SPINAL FUSION RECOVERY
}

by

\section{NAOMI EVE JOFFE}

A Thesis Submitted in Partial Fulfillment of the Requirements for the Degree of

\author{
Master of Arts \\ in the College of Arts and Sciences \\ Georgia State University
}


Copyright by

Naomi Eve Joffe

2009 
EVALUATION OF A BODY PILLOW TO AID

PEDIATRIC SPINAL FUSION RECOVERY

by

NAOMI EVE JOFFE

Committee Chair: Lindsey L. Cohen, Ph.D.

Committee: Chris Henrich, Ph.D.

Erin Tone, Ph.D.

Electronic Version Approved:

Office of Graduate Studies

College of Arts and Sciences

Georgia State University

May 2009 


\section{ACKNOWLEDGEMENTS}

I would like to take this opportunity to express my sincerest appreciation to my advisor, Lindsey L. Cohen, Ph.D., for his endless dedication, support, and encouragement both during the course of this project and throughout my graduate career thus far. Without his mentorship, this project and manuscript would not have been possible. I would also like to thank my committee members, Chris Henrich, Ph.D., Erin Tone, Ph.D., and Mike Kelly, Ph.D. for their thoughtful suggestions and comments. In addition, I would like to thank Donald Bearden and Kathy Rhodes for their assistance with data collection and all of the students in the Child Health and Medical Pain (CHAMP) Lab who are always offering their support and enthusiasm. I would also like to thank the children and their families who participated in this project, as well as members of the medical staff at Children’s Healthcare of Atlanta for their patience and assistance.

Finally, I would like to thank my wonderful and devoted husband, Ari, and our family for their continued love, support, and encouragement. Thank you also to all of my colleagues and friends at GSU and beyond who, by sharing their own experiences and supporting me through mine, have made this journey possible. 
TABLE OF CONTENTS

ACKNOWLEDGEMENTS

iv

LIST OF FIGURES

vi

1. INTRODUCTION

Purpose and Hypotheses

2. METHOD 8

$\begin{array}{ll}\text { Design } & 8\end{array}$

$\begin{array}{ll}\text { Participants } & 8\end{array}$

$\begin{array}{ll}\text { Measures \& Apparatus } & 10\end{array}$

$\begin{array}{ll}\text { Procedure } & 13\end{array}$

3. RESULTS 16

$\begin{array}{ll}\text { 4. DISCUSSION } & 24\end{array}$

$\begin{array}{ll}\text { REFERENCES } & 31\end{array}$

APPENDICES

APPENDIX A: FAMILY INFORMATION FORM 36

APPENDIX B: $\quad$ COMFORT RATING SCALE 38

APPENDIX C : NURSE REPOSITIONING RECORD 39

APPENDIX D : PAIN RATING SCALE $\quad 40$

APPENDIX E : PATIENT SATISFACTION SCALE 41

APPENDIX F : NURSE SATISFACTION SCALE 42

APPENDIX G : RESEARCH ASSISTANT COMFORT, PAIN, AND HEART RATE RECORD SHEET 


\section{LIST OF FIGURES}

$\begin{array}{lr}\text { Figure 1-1. Photographs of the BodyPillow }{ }^{\circledR} & 7\end{array}$

$\begin{array}{ll}\text { Figure 2-1. Study flow chart explaining sequence of procedures. } & 15\end{array}$

$\begin{array}{ll}\text { Figure 3-1. Participant self-reported comfort VAS ratings. } & 21\end{array}$

$\begin{array}{ll}\text { Figure 3-2. Participant self-reported pain VAS ratings. } & 22\end{array}$

$\begin{array}{lr}\text { Figure 3-3. Participant heart rate data. } & 23\end{array}$ 


\section{INTRODUCTION}

Each year, approximately 200,000 individuals in the United States undergo spinal fusion surgery to correct structural damage (Brainwaves, 2004). The spine is constructed of a series of vertebrae, which are held together and cushioned by connective tissue. This structure allows for movement including turning of the neck and back (North American Spine Society, 2006). Spinal fusion surgery may be warranted if (a) spinal movement becomes atypical or excessive, which is referred to as spinal instability; (b) an individual develops a spinal deformity such as scoliosis; or (c) an individual has a disc that has been slipping out of place (North American Spine Society, 2006).

The goal of spinal fusion is to straighten and stabilize the spine. Sections of bone from the hip are used to "fuse” specific vertebrae in order to correct spinal curvature and instability (Mayo Clinic Medical Services, 2006). Supplemental hardware such as nails, screws, and cages may also be used to hold vertebrae in place until the bone grafts heal (North American Spine Society, 2006). Although this type of surgery has been very successful in repairing past, and even preventing future spinal problems, a spine that has been fused can no longer grow at the surgery site (Advance, 2004). For this reason, it is most commonly performed on adolescents or adults who have reached their post-pubertal height (Mohanty, Kumar, Kishore, \& Babu, 2001); however, in some cases spinal fusion is performed on pre-pubertal children.

In general, recovering from surgery is difficult in that it can be time-consuming and

painful. The average hospital stay in the United States is 4.8 days (National Center for Health Statistics, Centers for Disease Control and Prevention, 2004). Although medications are helpful, pain following surgery is common and is reported as severe in more than $50 \%$ of patients (White, Pokrupa, \& Hoa Chan, 1998). Implementing the use of patient controlled analgesia (PCA) as a 
mode of medication administration has increased the adequacy of pain control (Shin, Kim, Kim, \& Kim, 2001) but the high estimates of patients still experiencing severe to moderate pain suggest that more needs to be done (Apfelbaum, Chen, Mehta, \& Gan, 2003; Dolin, Cashman, \& Bland, 2002).

Inadequately controlled pain can affect other domains in patients’ lives such as concentration, eating, sleep, and movement (Abbott, et al., 1992; Filos \& Lehmann, 1999). Further, post-surgery pain can lead to heightened distress and anxiety (Abbott et al., 1992). These side effects are most often observed in patients who have undergone thoracic, orthopedic, head-neck, and abdominal surgery due to the invasive nature of these surgeries (Huang, Cunningham, Laurito, \& Chen, 2001).

Spinal fusion surgery is one of the most complex and lengthy of all orthopedic surgical procedures (Mayo Clinic Medical Services, 2006). Typically, post-surgery, a patient will remain in the hospital for three to four days, but longer stays are not unusual (North American Spine Society, 2006). Although the spinal instabilities which lead to spinal fusion surgery are not always painful, recovery from this surgery is painful. Compared to other spinal surgery pain, the pain associated with spinal fusion is especially intense with some studies showing mean maximum post-surgery pain scores in the mid 70s on a $100 \mathrm{~mm}$ visual analog scale (North American Spine Society, 2006, Bianconi et al, 2004).

According to orthopedic surgeons, the ideal body position for recovery from spinal fusion surgery is lying on one’s side with the knees slightly bent (M. Jackson, personal communication, March 15, 2006). This position allows maximum healing of the surgical site and maintains proper spinal alignment (American Academy of Orthopaedic Surgeons, 2006). Ideally, patients should maintain still in this position for an hour before being turned to the other side of 
the body by the nursing staff; however, this is difficult due to continuous pain and discomfort. In order to assist patients in holding their position, nursing staff typically use numerous hospital pillows. Despite the best efforts of the staff, it is common for the patient to only be able to maintain a position for approximately fifteen minutes before requesting to be turned (M. Jackson, personal communication, March 15, 2006). Although there are no consistently used guidelines, this frequent repositioning is detrimental to the patient's proper healing, increases pain episodes, and requires repeated time and effort from the nursing staff (M. Jackson, personal communication, March 15, 2006).

Spinal fusion pain is partially managed by pharmaceuticals, such as Morphine Sulfate, Acetaminophen with or without hydrocodone or oxycodone, and Promethazine. Although these drugs provide some relief, patients continue to be uncomfortable and restless. In a study assessing the primary stressors for parents of adolescents undergoing spinal fusion surgery, $32.47 \%$ of parents postoperatively reported that pain was their main concern (Salisbury, LaMontagne, Hepworth, \& Cohen, 2007). In addition to pain not being fully managed, the medications administered can have side effects including nausea, urinary retention, depressed respiration, vomiting, and excessive sedation (Filos \& Lehmann, 1999). In a study examining individuals who had undergone surgery in the past five years, 94\% had experienced adverse side effects from their pharmaceuticals (Apfelbaum, Chen, Mehta, \& Gan, 2003). Nonpharmacological methods to decrease pain might increase comfort and decrease some of the need for pharmaceutical pain management.

Likely due to the relatively few number of procedures completed annually, there are few published studies of non-pharmaceutical spinal fusion pain management; however, there are a number of studies of non-pharmacological pediatric pain management approaches for other 
procedures (see Blount, Piira, \& Cohen, 2003). Findings from this literature might be relevant for spinal fusion pain and recovery.

In a review of the literature, Powers (1999) found that cognitive-behavioral packages are empirically supported for acute pediatric pain. Across the studies, a common ingredient was distraction. Distraction has been shown to be effective for pain management across a number of population’s painful medical procedures (for reviews, see Kleiber \& Harper, 1999; Piira, Hayes, Goodenough, 2002; Demore \& Cohen, 2005). Although distraction is a promising intervention, it appears to be primarily effective for brief, acute pain such as injections and might not be as useful for longer pain and discomfort, such as that associated with recovery from surgery.

Research has suggested that environmental modifications might be viable painmanagement strategies. For example, a number of studies have examined how the environment plays a role in pain management for premature babies (for a review, see Halimaa, 2003), and have shown that bright lights and noise might heighten infants' distress during procedures. Music is an additional environmental factor that has been shown to be helpful in the reduction of pain during and following painful medical procedures. Music played following intestinal surgery was found to significantly reduce patient pain (Good, Anderson, Ahn, Cong, \& Stanton-Hicks, 2005). Although music might be conceptualized as a distraction or relaxation intervention, it is also a simple environmental adjustment that might benefit patients. For spinal fusion surgery recovery, one environmental factor has been evaluated - sunlight. Researchers found that spinal fusion patients exposed to increased levels of natural sunlight reported less pain and had less demands on their PCA pumps (Walch, et al., 2005).

Positioning is another environmental factor that has been studied with a variety of populations. In a number of studies, positioning has been shown to have an important role in the 
comfort of premature infants during medical procedures (e.g., Halimaa, 2003). One study found that tucking the baby tight, holding the baby in one's arms, and swaddling the baby ease infants' recovery from painful procedures (Halimaa, Vehviläinen-Julkunene, \& Heinonen, 2001).

Environmental adjustments might be especially beneficial for spinal fusion recovery. Currently, hospital pillows are being used to aid in positioning and comfort during recovery but, these pillows have some drawbacks. Specifically, traditional hospital pillows are typically small, roughly 24” long by 18 ” wide. Thus, a number of pillows are needed in order to stack and stuff in various configurations to support the patient. Unfortunately, the pillows often fall and slide, causing mild to severe discomfort and the requirement of frequent readjustments.

A full body-sized pillow, specifically designed to help support a patient recovering from spinal fusion surgery might prove beneficial in a number of ways. The pillow might result in increased relaxation, decreased pain, decreased need for pain medication, and the ability to hold stationary positions for longer periods of time, ultimately helping the patient heal more quickly and comfortably. However, adequate justification and supporting data are necessary in order to change hospital policy and procedures, especially if additional costs are associated with the change (Finley \& McGrath, 2003).

Purpose and Hypotheses

This study aimed to test whether the BodyPillow ${ }^{\circledR}$, a pillow specially designed by Snoozer ${ }^{\circledR}$ for spinal fusion recovery (see figure 1-1), was more effective at increasing comfort and decreasing pain than hospital pillows in the recovery of spinal fusion patients. The study examined whether the BodyPillow ${ }^{\circledR}$ affected self-reported pain, the amount of pain medication requested, patient heart rate, self-reported comfort level, and the number of repositionings required. 
It was expected that the BodyPillow ${ }^{\circledR}$ would increase comfort and decrease pain. This expected increase in comfort and decrease in pain would be evident through higher self-reported levels of comfort and lower self-reported levels of pain, lowered heart rate, and fewer demands on the patients' analgesic pain pumps during the specially-designed pillow condition. 

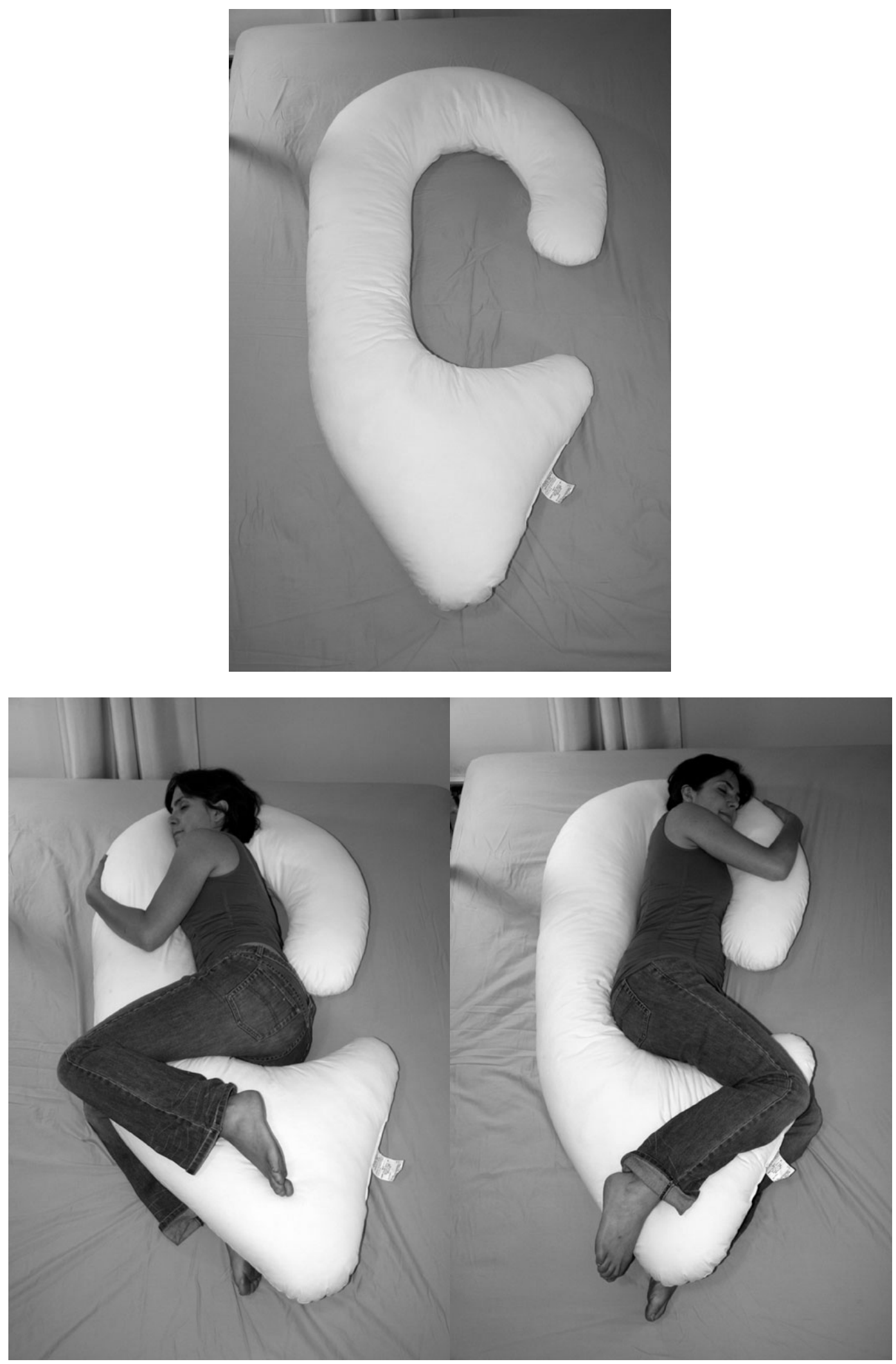

Figure 1-1. Photographs of the BodyPillow ${ }^{\circledR}$. 


\section{METHOD}

\section{Design}

A multiple-baseline design across individuals was used in this study. This single-subject design was selected for several reasons. First, single-subject designs are ideal for applied research and studies involving clearly specified target behavior because they focus on the treatment of the individual client; researchers are able to focus on each individual's response to treatment and modify treatment if necessary rather than evaluate average group response to a uniform intervention (Kazdin, 1998). Second, given that spinal fusion surgery is relatively rare, with approximately 200,000 surgeries being performed annually in the United States, a group design would be difficult (Brainwaves, 2004). Third, since there are no published studies examining comfort and positioning measures for this population, single-subject designs allow flexibility in modifying and developing the treatment during the study. In turn, results might inform general approaches to comfort that might be applicable across patients, which can be evaluated in subsequent group design studies. Due to the clinical nature of this study, it was important that the design not require removal of something that could potentially be helpful to the patients. Using a multiple-baseline design allowed the intervention to be introduced and not removed as is the case in a single-subject reversal design.

\section{Participants}

Participants included 3 female and 1 one male pediatric patient, ranging in age from 13 to 18 years who underwent spinal fusion surgery at a children's medical center in the southeastern United States. All four participants were referred for spinal fusion surgery due to a diagnosis of Scoliosis. Specific inclusion/exclusion criteria included the following: First, only adolescents between the ages of 13 and 18 were included. The age range was selected because of the nature 
of the procedure. Spinal fusion terminates the growth of the spine and is therefore typically performed during adolescence after the patient has reached normal adult height (Advance, 2004). Second, all participates had to be English-speaking as this was the language of the researchers performing consent and data collection. Third, if a patient reported a high level of comfort (75 or greater on a 100-point scale) and low level of pain (25 or lower on a 100-point scale) during the first 30 minutes of baseline data collection, the patient was discontinued and another patient was enrolled. This criterion was set because it would be unethical and medically irresponsible to disturb and change the pillows of a patient who is relatively comfortable and not in pain. To preserve confidentiality, all patients were assigned pseudonyms in this study.

Amber. Amber was a 14-year-old Caucasian female diagnosed with scoliosis at age 14. Amber lived at home with her five siblings, her mother, and her step-father. Amber reported that she enjoyed spending time with her siblings and liked being part of a large family.

Belinda. Belinda was a 14-year-old Portuguese female diagnosed with scoliosis at age 14. She lived at home with her 9-year-old sister, her mother, and her father. She grew up speaking both English and Portuguese. During the study both of her parents were present. Belinda appeared polite as evidenced by her consistently saying "Thank you” when interacting with the research assistant and nursing staff.

Camile. Camile was an 18-year-old African American female diagnosed with scoliosis at age 11. Camile presented as very mature; she talked about her plans following graduation and spoke diplomatically about a nurse who had difficulty accessing her vein for her PCA pump. She had no siblings and lived at home with her mother and father. Both of Camile’s parents were present during the study. 
Daniel. Daniel was a 13-year-old Caucasian male diagnosed with scoliosis at age one. He appeared somewhat angry and resentful while in the hospital. For example, when the physical therapist informed him that he would need to spend some time sitting in a chair, he responded by saying, "Why do I have to do this? It’s not fair!” His parents were divorced and he lived at home with his mother and his 24-year-old brother. Daniel's mother was present for the entirety of data collection and his father was present intermittently. Daniel's father appeared to have a stern and strict parenting style. For example, he told Daniel, “You've got to be able to take care of yourself,” and "You're not in that much pain, boy!”

In addition to the 4 participants who were enrolled, 3 additional adolescents were considered for the study but were excluded from participation. One 16-year-old female reported high levels of comfort and low levels of pain following surgery and thus did not meet inclusion criteria. A 16-year-old male's data during the baseline phase never stabilized so he was unable to be switched to the BodyPillow ${ }^{\circledR}$ condition. Finally, a 15-year-old female experienced complications during her surgery and was transferred to the Pediatric Intensive Care Unit after spinal fusion and was not able to participate.

\section{Measures and Apparatus}

Demographics. The parents of adolescents participating in the study completed a family background information form (Appendix A). Questions assessed child gender, child age, child racial/ethnic identity, parent age, parent education level, family income, and child's health history. These data were used for descriptive purposes.

Comfort. Children’s level of comfort following surgery was assessed using a visual analog scale (VAS) (Appendix B). Patients were asked to indicate their level of comfort by making a mark on a $100 \mathrm{~mm}$ horizontal line anchored with the terms "Very comfortable” to 
"Very uncomfortable”. VASs are commonly used in pediatric psychology research, have been shown to be valid and reliable, and result in less clustering of scores than is found with likerttype measures (McGrath, 1990; Varni, Walco, \& Wilcox, 1990). Given that comfort was the primary dependent variable, stability on this measure determined condition change.

The number of times a participant requested to be repositioned was also used as a marker of comfort level. The Nurse Repositioning Record (Appendix C) was used by the research assistant (RA) to document the number and nature of patient repositionings. Each nurse reported to the RA whether they were called into the room by the patient/parent, which pillow type was being used and in what configuration, whether they switched the pillows from one type to another, and how they repositioned the child.

Pain. Adolescents' self-reported pain due to the surgery was assessed using a VAS asking them how much pain they were experiencing, from "No pain” to "Extreme pain" (Appendix D). This scale was administered every 10 minutes for the duration of the study.

Heart rate was recorded from the heart rate monitor by the RA every 10 minutes. Heart rate has been frequently used as a general physiological indicator of pain, with higher heart rates indicating more pain. Further, it has been shown that heart rate may decrease when patients feel calm, soothed, and are distracted from pain (Sweet \& McGrath, 1998).

Children recovering from spinal fusion surgery at the study facility receive Morphine Sulfate via a PCA pump. PCA pumps allow the patient to release 0.2 milligram/kilogram doses of Morphine into their system as they deem necessary, however, the pump is set to allow a set maximum amount of medication of five milligrams every two hours. The PCA pump electronically monitors and stores data indefinitely as long as the pump is plugged in and kept on. The pump calculates and reports the amount of medication administered over the past hour 
and also keeps track of the specific times that requests were made and how much medication was received at each of those requests. The nurses retrieved the medication off of the PCA pump every two hours and the RAs recorded how many demands the patient made and how many administrations the patient received. Each time the patient made a demand on the PCA pump within the limits of their allowed medication dosage, one dose was "pumped” in through their intravenous.

Patient satisfaction. Patients completed a patient satisfaction scale (Appendix E), a visual analog scale assessing how satisfied they were with both the BodyPillow ${ }^{\circledR}$ and the hospital pillows. This visual analog scale asked patients to make a mark on a $100 \mathrm{~mm}$ horizontal line to indicate their level of satisfaction with each pillow condition. The scale had the anchors "Very unsatisfied” and "Very satisfied”. Patients also had the opportunity to record any additional comments regarding their satisfaction levels.

Nurse satisfaction. Nurse satisfaction was also assessed (Appendix F). In order to assess these two constructs the nurses completed four visual analog scales. The first two scales addressed the efficiency of each of the pillow types ranging from "Very inefficient” to "Very efficient”. These indicated whether the specially designed pillow was any faster and easier to use for the nurses than hospital pillows. The second scales addressed how comfortable the nurse perceived the child to be ranging from "Very uncomfortable" to "Very comfortable". Nurses were also able to record any additional comments they had regarding the two pillow types.

BodyPillow ${ }^{\circledR}$. Whereas the usual pillow configuration for spinal fusion patients involves a number of standard size disposable hospital pillows, the BodyPillow ${ }^{\circledR}$ was designed in such a way that only one pillow is necessary (figure 1-1). This pillow is c-shaped and specifically designed to fit around the patient's body, supporting the patient from the front and the back. It is 
approximately four and a half feet long, two and a half feet wide, and one foot thick. The pillow case was especially designed for the hospital environment in that it was made of a fabric that was resistant to fluids and disposable after use.

Procedure

Pre-surgery. Children scheduled to undergo spinal fusion surgery and their parents were informed about the study by medical center staff during a pre-operation visit and were then directed to a research assistant (RA) to receive more information. The RA provided the family with additional details, including a description of the two pillow types. After providing consent to participate, the parents completed the background information form.

Post-surgery. Surgery was typically completed in the late afternoon, and children were transferred to a non-surgical floor either late that evening or early the following morning. The baseline phase of the study began in the morning on the day after surgery on the recovery unit and continued until the child had both the hospital pillow condition and the BodyPillow ${ }^{\circledR}$ condition.

At 8:00am, the baseline began and the research assistant began recording repositioning and pillow information. A number of patients were sleeping soundly and were unable to provide comfort and pain data until later in the morning. In these cases, the RA monitored the patient if he or she woke and did continue to record the heart rate. During the baseline period, all patients used hospital pillows. As is the standard of care, approximately eight small hospital pillows were used for a patient. The nurse was called to switch each patient from the hospital pillow condition to the BodyPillow ${ }^{\circledR}$ condition by the research assistant when data from the comfort VAS was stable. Consistent with other pain studies using VASs, data stability was defined as a difference of $12 \mathrm{~mm}$ or less on a visual analog scale across four consecutive data points (Gallagher, 
Liebman, \& Bijur, 2001). According to protocol of multiple-baseline designs across individuals, the baseline of each subsequent patient was held for four data points longer than the previous patient in order to control for the effect of time on comfort level.

A research assistant (RA) was involved for the course of the study. Beginning at 8:00am, the RA entered the patient's room, recorded the patient's heart rate, and asked the patient to complete the comfort and pain VASs (Appendix G). When the patient was asleep, the RA would gently attempt to rouse the patient but would wait until the next data collection point if the patient did not wake with soft nudging and voice commands. After obtaining the ratings, the RA left the room. The RA returned to record heart rate and have the patient complete these brief scales every 10 minutes for the duration of the study. After four stable data points on the comfort VAS that were free of an upward trend, the RA requested that the nurse assist the patient in switching from the hospital pillows to the BodyPillow ${ }^{\circledR}$. The RA continued collecting data from the patient for approximately four hours. At the end of the data collection period, the patient and nurse each completed the satisfaction scales. Each participant was given the option to take the BodyPillow ${ }^{\circledR}$ home after the study.

Aside from switching the pillow type for the study, the nurse repositioned patients based on patients' requests and had the RA record those changes in the Nurses' Repositioning Record. The nurses’ comments reflected whether it was a “small” repositioning (i.e., rearranging supporting pillows but not moving patient) or if the child was turned to a new position (i.e., moving patient from resting on one side of body to resting on the other). For an overview of study procedure, see figure 2-1. 
8:00a Enter patient's room and administer Comfort and Pain Scales, record heart rate, and leave room

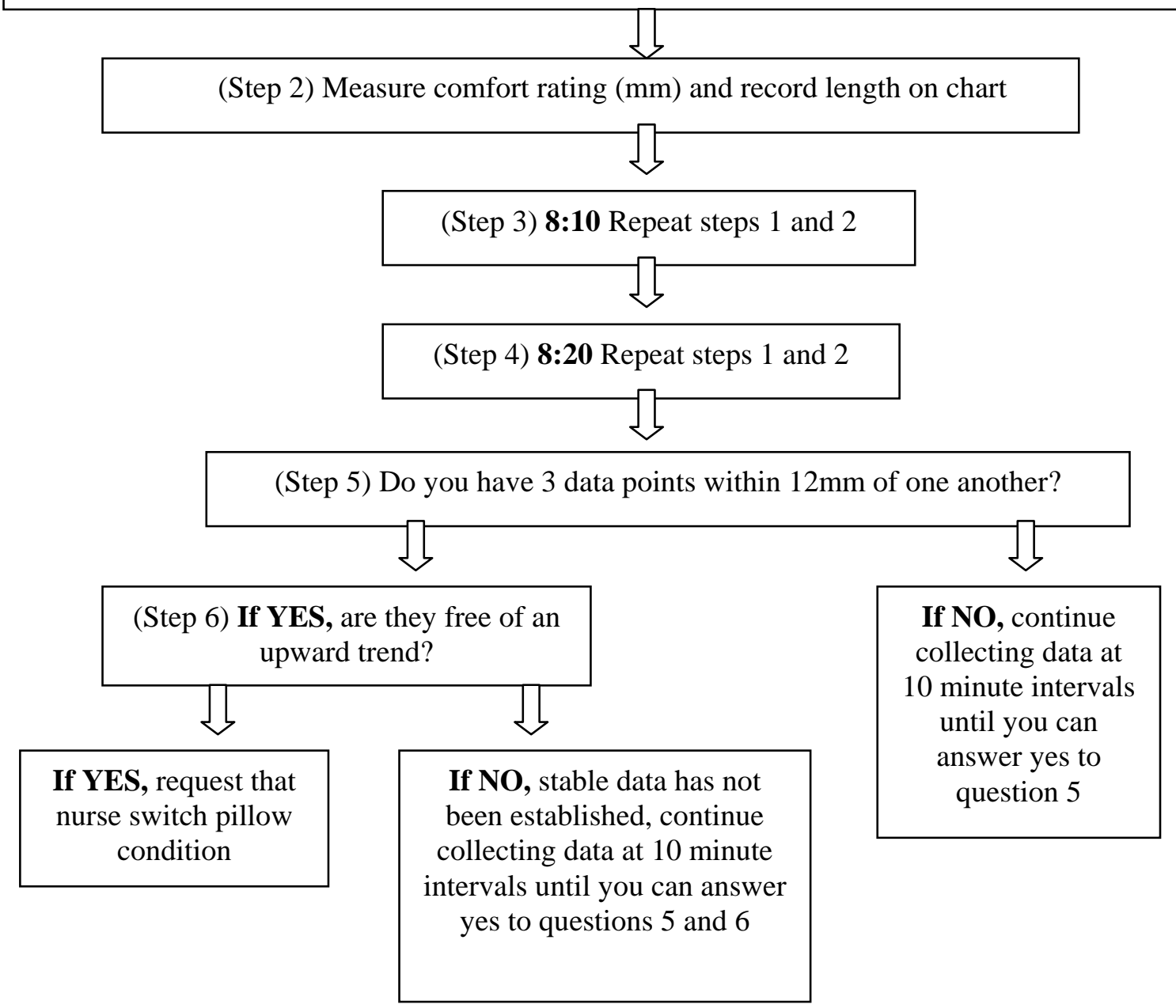

Figure 2-1. Study flow chart explaining sequence of procedures. 


\section{RESULTS}

Data evaluation in single-subject designs typically consists of visual inspection of the data points. In multiple-baseline designs, experimenters make a prediction of an individual's continued performance using baseline data, present an intervention, which is expected to violate the baseline prediction, and then verify the results via replication (Kazdin, 1982). To demonstrate replication in the current study, multiple participants were enrolled. To help establish that change in comfort resulted from the BodyPillow ${ }^{\circledR}$ and not simply from time lapse, the BodyPillow ${ }^{\circledR}$ was presented at later time points for each participant (i.e., varying baselines).

To increase the reliability and validity of visual inspection, data were analyzed using a refined visual inspection technique, the conservative dual-criteria (CDC) method (Fisher, Kelley, \& Lomas, 2003). The CDC method, which is a modified version of the split-middle (SM) method (Kazdin, 1982; Parsonson \& Baer, 1986; White, 1974), works to decrease the number of Type I and Type II errors made by the SM method. The data are entered into an Excel program developed by Fisher, Kelley, and Lomas which generates CDC criteria lines, which are added to the subject's data before analysis. In Excel, one line is generated using the baseline mean and the other uses the baseline intercept and slope to generate the least squares trend line. As described by Fisher, Kelley, and Lomas, for results to be deemed significant, a certain number of data points must fall above each of these lines. The number of points necessary is calculated by the computer program and is determined by applying the binomial formula to calculate the probability of that number of data points falling above the least squares trend line by chance. The number of points required to conclude there is a reliable treatment effect varies depending on the number of data points collected during baseline. For example, for a participant with 19 baseline data points, 13 of them must fall above both criterion lines to conclude that there is a reliable 
treatment effect, whereas, for 23 data points, 15 of them must fall above the criterion lines. Data was analyzed first traditionally, with comparison of means, and then more conservatively, with the CDC method.

Amber. Amber showed a 152\% increase in comfort after switching to the BodyPillow ${ }^{\circledR}$ with 11 (9 required) data points in the BodyPillow ${ }^{\circledR}$ condition falling above both the baseline mean and least squares trend lines as graphed through the CDC method. This was an average change of $45 \mathrm{~mm}$ out of $100 \mathrm{~mm}$ between conditions (see figure 3-1). Amber received no repositionings over the course of data collection aside from getting up to go the bathroom, moving to the chair with physical therapy, or having her pillows switched from hospital to BodyPillow ${ }^{\circledR}$.

Regarding pain neither the CDC method of analyses or comparison of means showed any significant difference in pain ratings between hospital pillows and the BodyPillow ${ }^{\circledR}$ for Amber. Her pain rating averaged at 32mm and 33mm respectively (see figure 3-2). Also, in the comparison of means, Amber showed no significant differences in heart rate between conditions (see Figure 5). According to the CDC method, Amber had a significant increase in heart rate from hospital pillows to BodyPillow ${ }^{\circledR}$, but this difference equates to an average difference of 5.27 beats, which is not clinically significant (Gallagher, Liebman, \& Bijur, 2001). Amber had only two met demands and one unmet demand on her PCA pump, which was prompted by the nurse before switching from the hospital pillows to the BodyPillow ${ }^{\circledR}$.

Satisfaction findings from VASs, ranging from 0-100 with higher scores reflecting more satisfaction, showed that Amber was very unsatisfied with the hospital pillows, giving them a rating of 5mm, and very satisfied with the BodyPillow ${ }^{\circledR}$ giving it a rating of $73 \mathrm{~mm}$. She commented that "[the BodyPillow $\left.{ }^{\circledR}\right]$ works much better than the hospital pillows” and is "more 
comfortable and much easier to lay with”. Amber’s nurse rated the BodyPillow ${ }^{\circledR}$ as more efficient than the hospital pillows at $71 \mathrm{~mm}$ compared to $25 \mathrm{~mm}$, respectively. She rated both pillow types as equally comfortable at $79 \mathrm{~mm}$ and $80 \mathrm{~mm}$. She commented that the "triangle for the knees [on the BodyPillow ${ }^{\circledR}$ ] is very useful”.

Belinda. Belinda demonstrated improvement in her comfort level when switched to the Bodypillow ${ }^{\circledR}$ (see figure 3-1). Although she only had 5 of 6 necessary data points above the criteria lines, the average change of $12.52 \mathrm{~mm}$ between conditions was significant according to prior research that has used an average difference of $12 \mathrm{~mm}$ or more on a visual analog scale as significant (Gallagher, Liebman, \& Bijur, 2001). Further, Belinda showed a 42\% increase in comfort. Belinda did not receive any repositionings during data collection. Belinda was moved to to sit in a rocking chair by physical therapy after having switched to the BodyPillow ${ }^{\circledR}$. Belinda had been reporting nausea during the course of the morning and vomited once moved to the chair. Due to feeling ill, Belinda requested that the research assistant not collect any more ratings for her after this incident so data collection was stopped.

Neither the CDC method of analyses or comparison of means showed any significant difference in pain ratings between hospital pillows and the BodyPillow ${ }^{\circledR}$ for Belinda. Her average pain ratings were 53mm and 65mm (see figure 3-2). Another measure of pain, average heart rate, did not differ significantly between pillow types for Belinda (see figure 3-3). In terms of analgesia administered, Belinda had two met demands out of two requests during her hour using the hospital pillows and 3 met demands out of 5 requests during her hour using the BodyPillow ${ }^{\circledR}$.

Patient satisfaction ratings were not collected for Belinda because she left the hospital before completing the form. Satisfaction ratings were not collected for Belinda's nurse either, as 
this nurse was very busy at the end of data collection, and the research assistant did not receive her form after the study was completed.

Camile. Camile showed improvement in her comfort level when she switched from hospital pillows to the BodyPillow ${ }^{\circledR}$ (see figure 3-1). She demonstrated an 18mm difference between conditions and a 43\% increase in comfort with 7 of 7 needed data points falling about the two lines. In terms of repositioinings, Camile requested that the nurse reposition her pillows twice while using the hospital pillows but no times when using the BodyPillow ${ }^{\circledR}$. Both of these repositionings were done after Camile had held one position for approximately 90 minutes.

For Camile, average pain ratings were $17 \mathrm{~mm}$ for hospital pillows and $19 \mathrm{~mm}$ for the BodyPillow ${ }^{\circledR}$ (see figure 3-2). This difference was not significant with either method of analysis. Camile’s average heart rate was not significantly different from the hospital pillows to the BodyPillow® (see figure 3-3). As Camile’s PCA pump was unhooked part way through the study, no analgesic medication data was collected for her.

In terms of satisfaction, Camile reported that both pillow types were equally comfortable giving them moderate satisfaction ratings of $47 \mathrm{~mm}$ and $48 \mathrm{~mm}$ and writing that the BodyPillow ${ }^{\circledR}$ “is comfortable”. The nurse for Camile showed no preference in pillow types giving ratings of $62 \mathrm{~mm}$ and $64 \mathrm{~mm}$ for efficiency and 51mm and 57mm for the comfort levels of the hospital pillows and BodyPillow ${ }^{\circledR}$, respectively.

Daniel. According to both comparison of means and the more conservative CDC method, Daniel reported that the Bodypillow ${ }^{\circledR}$ was significantly more uncomfortable than the hospital pillows with 5 of the needed 5 data points below the criteria lines. Daniel reported a 53\% decrease in comfort with the Bodypillow ${ }^{\circledR}$ with an average change in comfort of 23mm (see figure 3-1). When Daniel was moved from the hospital pillows to the BodyPillow ${ }^{\circledR}$, his father 
assisted the nurse in the transition. Daniel's father appeared forceful when moving Daniel and sat him up quickly. Daniel grimaced and winced considerably during this move. Daniel requested that the staff “stop making [him] move”. Anecdotally, the nurse and research assistant reported that the BodyPillow ${ }^{\circledR}$ was not in an ideal position when Daniel requested that the nurse not move him, and thus he was left in this position. Daniel did not request or receive any repositionings while using the BodyPillow ${ }^{\circledR}$. He was repositioned twice when using the hospital pillows. On both occasions, the repositioning was initiated by the nurse.

Daniel's pain ratings were similar for the pillow types; his pain ratings averaged at $41 \mathrm{~mm}$ for the hospital pillows and 51mm for the BodyPillow ${ }^{\circledR}$ (see figure 3-2). Heart rate information was not recorded for Daniel because the nursing staff removed his when repositioining him and did not reattach it. In terms of analgesia, Daniel, although connected to a PCA pump, was given an injection of pain medications before beginning the study and after finishing participating. He had no PCA requests during either study condition. The injected pain medication appeared to make him more heavily sedated than individuals using PCA pumps; he slept for the majority of the study and was woken up for many of his comfort and pain ratings.

Daniel reported being very satisfied with the hospital pillows, giving them a rating of $86 \mathrm{~mm}$ on the VAS, but reported being very unsatisfied with the BodyPillow ${ }^{\circledR}$ giving it a rating of $4 \mathrm{~mm}$ on the VAS. Daniel's nurse rated the BodyPillow ${ }^{\circledR}$ as less efficient, 38mm versus $80 \mathrm{~mm}$, but more comfortable, $76 \mathrm{~mm}$ versus $29 \mathrm{~mm}$, than the hospital pillows. 


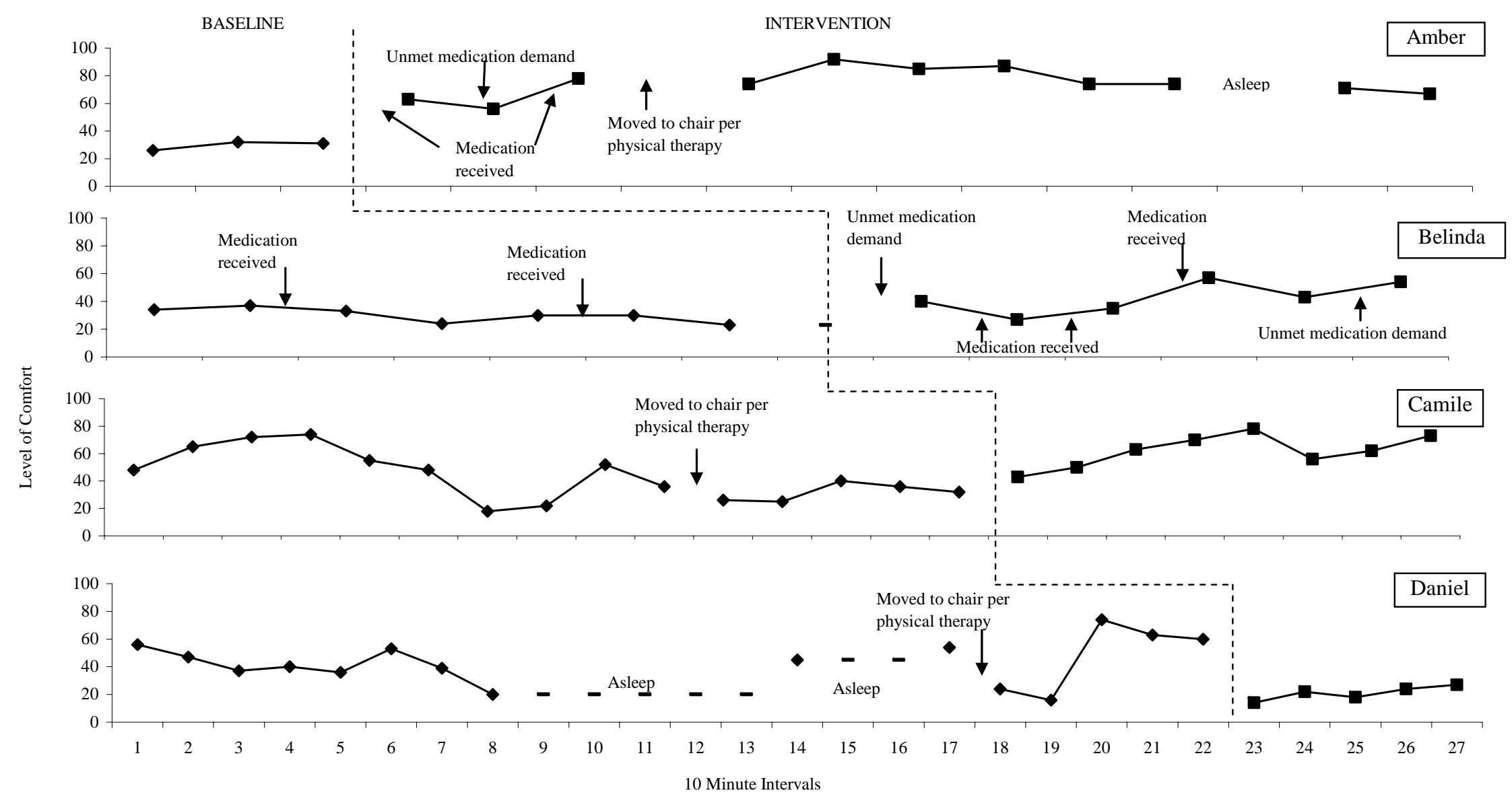

Figure 3-1. Participant self-reported Comfort VAS ratings. 


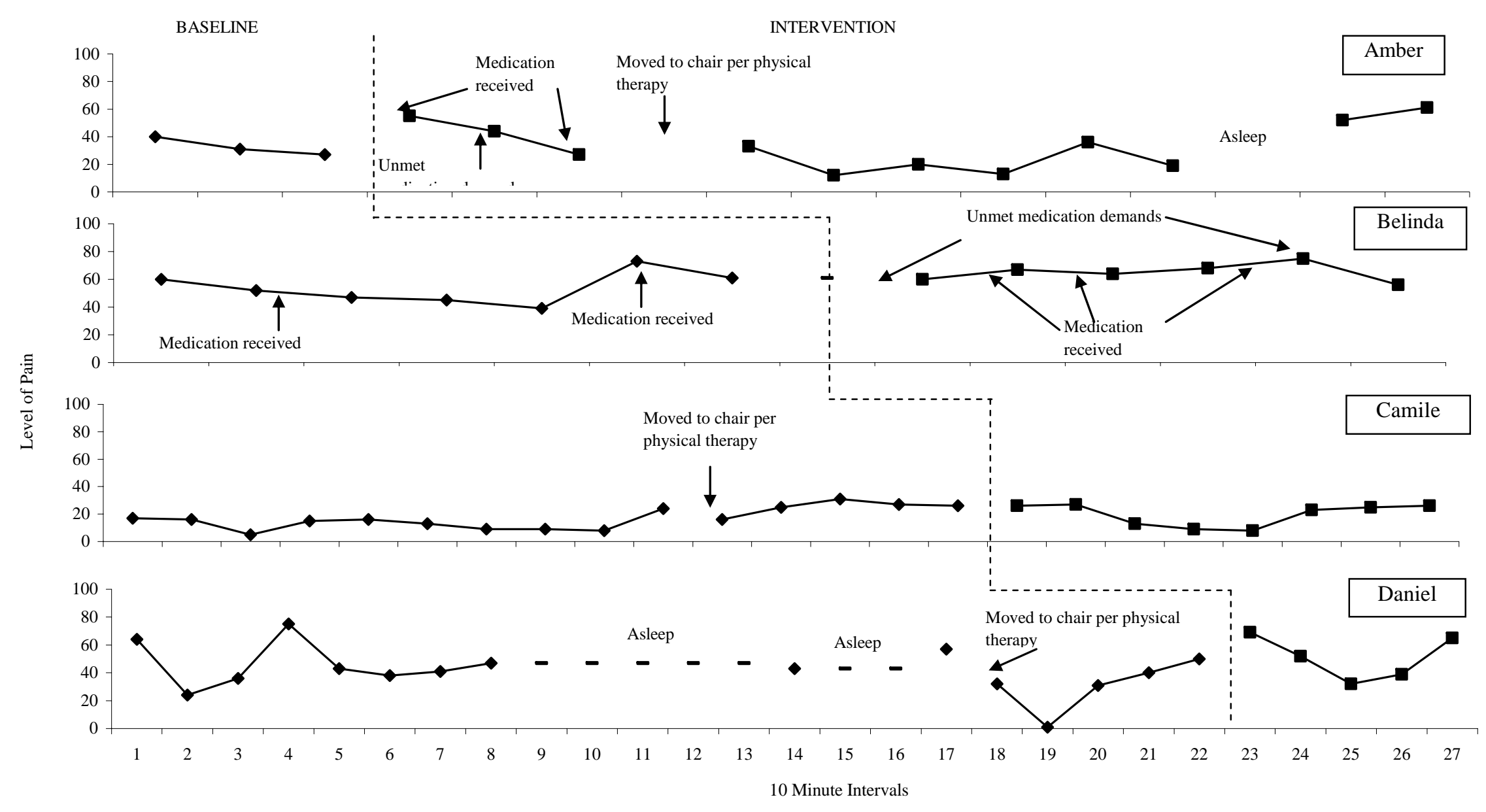

Figure 3-2. Participant self-reported Pain VAS ratings. 


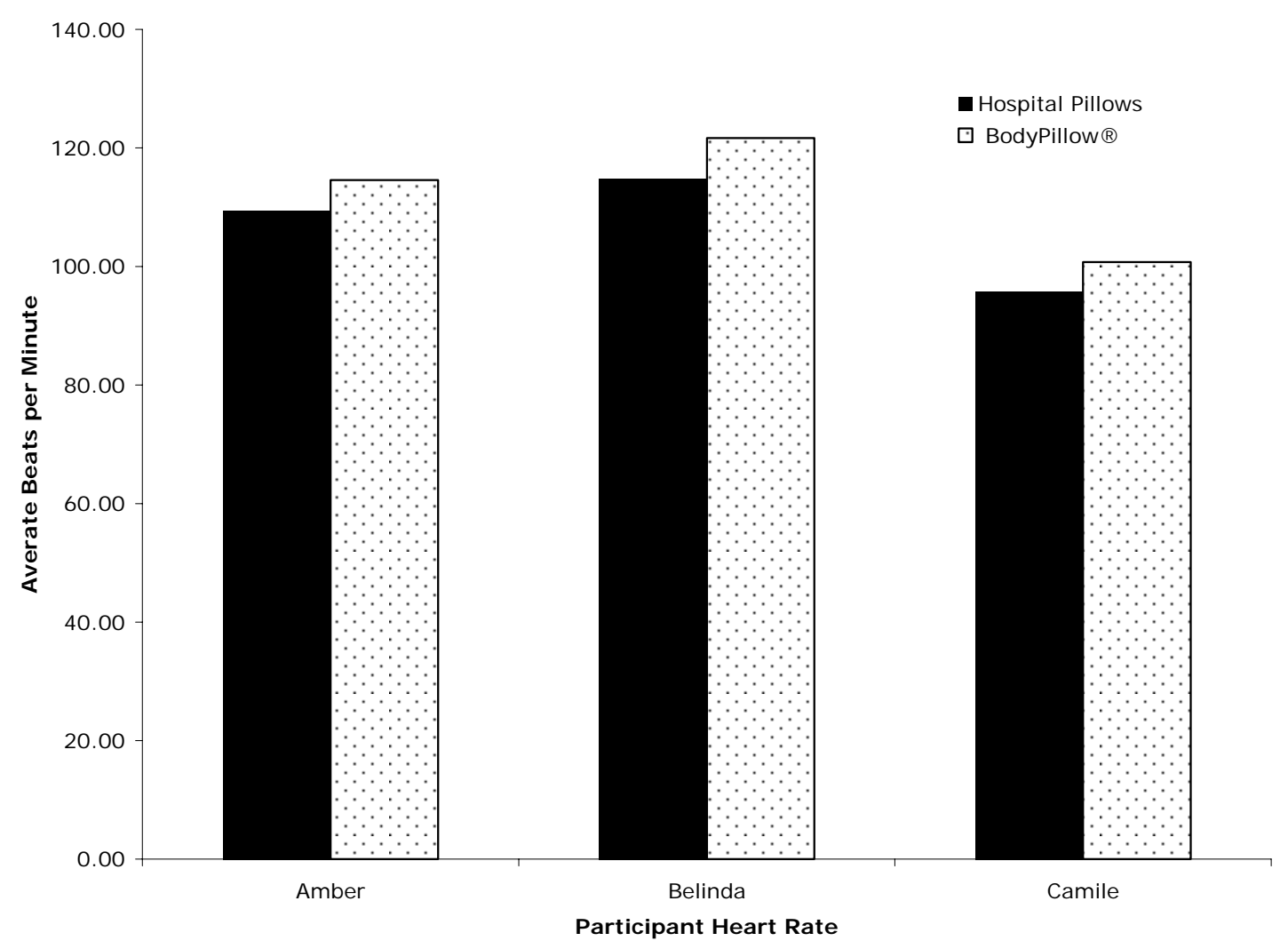

Figure 3-3. Participant heart rate data. 


\section{DISCUSSION}

Spinal fusion surgery is uncomfortable and recovery is made difficult by patients being required to lie still in specific positions in order to promote healing. It was hypothesized that the BodyPillow ${ }^{\circledR}$ would increase comfort and decrease pain in these patients as compared to the standard of care of using three to eight small hospital pillows. Results partially supported these expectations with Amber, Belinda, and Camile reporting higher levels of comfort. Though satisfaction ratings were not collected for Belinda, Amber reported qualitatively that the BodyPillow ${ }^{\circledR}$ was “more comfortable and much easier to lie with”. Camile also reported that the BodyPillow ${ }^{\circledR}$ “is comfortable”.

The number of repositionings requested, an intended marker of discomfort, was less than expected overall. Although these patients reported relatively few repositionings, nurses reported anecdotally that typically frequent repositioning requests are made by this patient population. For Camile and Daniel, the two patients who requested repositionings, the data indicated that more repositionings were requested with the hospital pillows than the BodyPillow ${ }^{\circledR}$ suggesting that the patients were more comfortable when using the BodyPillow ${ }^{\circledR}$.

In contrast to expectations, the BodyPillow ${ }^{\circledR}$ did not appear to impact pain. Specifically, patient VAS report, heart rate, or analgesia use did not indicate differences between conditions for any of the four participants. Although most of the literature seems to view pain and discomfort as directly related (e.g. Corff, Seideman, Venkataraman, Lutes, \& Yates, 2006), this study suggests that they may actually be two distinct constructs. Average pain ratings were lower than expected given data from other studies within this population (e.g. Bianconi et al., 2004). This overall difference may have been due to recent advances in pain management in this population. The amount of pain medication administered was less than expected by the nurses 
overall. Researchers found that medication was administered somewhat differently for different patients, with some patients, such as Daniel, receiving larger doses via injection instead of through their PCA pump. Notably, these medications are strong and long-acting and often result in periods of fairly heavy sleep, and consequently, few requests for medication. These data are consistent with nurse anecdotal reports that the patients often report that their pain is controlled but that they are unable to get comfortable when in recovery. In other words, there might have been a floor effect for pain with each participant's pain scores clustering around the same low levels for both hospital pillows and the BodyPillow ${ }^{\circledR}$.

Although results for Amber, Belinda, and Camile are fairly consistent, Daniel's reports of being less comfortable with the BodyPillow ${ }^{\circledR}$ are notable. There are several possible reasons for this reaction. First, Daniel was the only male and appeared to be receiving different messages about pain and his recovery from his father than the other participants received from their parents. Daniel's father was stern, commenting, "You're not in that much pain boy”, "You’ve got to be able to take care of yourself", and to his mother, "You can’t be easy on him”. Thus, Daniel might not have wanted to appear to his father that he needed assistance from the large BodyPillow ${ }^{\circledR}$. Second, when Daniel was switched from the hospital pillows to the BodyPillow ${ }^{\circledR}$, his father was involved and was not gentle with the repositioning. This was a striking difference from the other participants whose parents were gentle in their assistance with repositionings. This interaction might not only have caused Daniel more discomfort due to sudden movement but also resulted in him requesting to discontinue being moved, which led to the poor positioning of the BodyPillow ${ }^{\circledR}$ and, in turn, greater discomfort. Third, Daniel had his pain medication administered in a different way, which led to him sleeping heavily throughout the study; waking him up for data points likely influenced not only his mood, but his ability to 
accurately rate his comfort level. Frustration about being woken up frequently may have resulted in him giving lower ratings than he might have otherwise. Fourth, given that Daniel received his only injection of pain medication at seven in the morning, approximately an hour and half before beginning data collection, it is possible that in the early afternoon when he was switched to the BodyPillow ${ }^{\circledR}$, his pain medication may have been wearing off. Lastly, multiple nurses throughout the course of data collection anecdotally reported to the research staff that they perceived adolescent male spinal fusion patients as "bigger wimps” and "more whiney" than their female patients. Whether this is accurate or not, it is likely that these nurses’ perceptions impact their behavior toward male patients, which in turn might influence how males experience post-surgery comfort and pain.

Doing research in a medical setting such as a hospital can be challenging as there are often confounding variables that are out of the researchers' control. However, single-subject methodology can highlight some of the subtleties and nuances lost in group-design studies. For example, in the current study, physical therapists came to work with the patients in the middle of the data collection session. Physical therapy required that the patients move out of bed to sit in a rocking chair for one hour the morning after surgery. This visit occurred at different points in data collection for each participant. In Amber’s case, it occurred after her switch to the BodyPillow ${ }^{\circledR}$ and she moved back to the BodyPillow ${ }^{\circledR}$ afterward. Similarly, Belinda completed physical therapy after she had switched to the BodyPillow ${ }^{\circledR}$ but coincided with the end of her data collection. Physical therapy for both Camile and for Daniel occurred in the middle of their time using the hospital pillows. The physical therapist reported that this is typically painful for these patients but an important step in maintaining their mobility. Amber, Belinda, Camile, and Daniel found this extremely painful as evidenced by an increase in medication administration, 
self-report, and, in Belinda's case, nausea and vomiting. The physical therapist had the participants push the PCA pump before she moved them.

This study contributes to the current body of research in several ways. The findings from Amber, Belinda, and Camile are consistent with other research that shows manipulations in the environment can impact the patient. Most of these studies, however, focus on pain, not comfort (e.g., Halimaa, Vehviläinen-Julkunene, \& Heinonen, 2001; Good, Anderson, Ahn, Cong, \& Stanton-Hicks, 2005). Additionally, environmental impact studies in health psychology have predominately focused on environmental factors in hospital wards, such as lighting and noise in the neonatal intensive care unit. This study is unique in that it evaluates a specific apparatus designed for patient comfort and recovery. Further, research has suggested that spinal-fusion surgery produces extreme pain and discomfort and that untreated pain can have significant longterm effects (Abbott, et al., 1992; Filos \& Lehmann, 1999; Mayo Clinic Medical Services, 2006). Although pain data in the current project were low, this is a population that deserved further attention due to reports of high discomfort. In addition, a significant part of recovering from spinal fusion is maintaining proper positioning. This is the first study to date to have examined the impact of an environmental factor related to positioning on comfort and pain during spinal fusion recovery. This environmental factor, the BodyPillow ${ }^{\circledR}$, appears to be fairly easy for nurses and caregivers to utilize as an intervention for comfort. Nursing staff has many responsibilities within the busy hospital environment and would not be able to implement an intervention that was too complex or decreased their overall efficiency. Caregivers are often present for their child's recovery and are eager to increase their child's comfort, the BodyPillow ${ }^{\circledR}$ is something that they can help position and may result in less repositionings overall compared to multiple hospital pillows. 
There are several limitations of this study that should be noted. First, given that a singlesubject, multiple baseline design was used, findings will likely not generalize well to other populations. A second limitation was that Amber, Belinda, Camile, and Daniel were each on medications that might have influenced comfort and responding. This may be even more likely for Daniel given that he slept heavily for much of the study. A third limitation was that in addition to the manipulated independent variable, there were other variables that the research team noted, which likely influenced the data. For example, with Amber, physical therapy came just after she was switched to the BodyPillow ${ }^{\circledR}$. This likely impacted the ratings following their visit and may have even suppressed some of the effects of the BodyPillow ${ }^{\circledR}$. Due to this visit from physical therapy, it is difficult to know whether comfort ratings would have been higher or pain ratings lower with the BodyPillow ${ }^{\circledR}$. For Belinda, it would have been helpful to have had a few more data points when she was using the BodyPillow ${ }^{\circledR}$, but because she was feeling ill following the visit from physical therapy, the research team opted to end her data collection. For Camile, her PCA pump was removed and she could not self-administer pain medication and these data were not available. Daniel was influenced by a number of variables that the research team was unable to control including his medication administration route, the fact that he slept through much of data collection, and his father's authoritative caretaking style. These challenges speak to the complexity of clinical research in the hospital environment and the value of singlesubject methodology at highlighting idiosyncratic but important variables. These clinical nuances should be carefully considered when working with post-surgery spinal fusion patients.

These data appear sufficiently conclusive to suggest a follow-up study evaluated via a group design. A larger sample would allow the use of inferential statistics, which would provide greater confidence in whether the BodyPillow ${ }^{\circledR}$ is helpful to most post-spinal fusion surgery 
adolescents. Current findings detail some of the variables (e.g., physical therapy sessions, medications, gender) that should be controlled (e.g., stratified random sampling) in a group design study. In addition to controlling for some of these variables, future studies could incorporate observational measures in addition to self-report and physiological measures. Including observational data would provide more information about patient's pain levels and interactions within the family and also between the family and hospital staff. It would also be helpful for future studies to have more specific inclusion and exclusion criteria that would address differences in potentially important variables such as parent involvement. In addition to looking more closely at potential participants, gathering additional information about the nurses involved and how they interact with the participants would be helpful as well. Research shows that there are a wide range of nurse behaviors surrounding assessment and treatment of pediatric pain and it would be informative to study this as a potential variable in future research (Melhuish \& Payne, 2006). Results from these studies might provide additional support for the BodyPillow ${ }^{\circledR}$, and might better generalize to other populations. Additional studies might manipulate factors found this study to be potentially relevant (e.g., gender, medication) and determine whether the BodyPillow ${ }^{\circledR}$ is more effective in particular situations or with specific populations.

Amber, Belinda, and Camile each found that the BodyPillow ${ }^{\circledR}$ increased their comfort as they recovered from spinal fusion surgery; Daniel reported that he was less comfortable with the BodyPillow ${ }^{\circledR}$. Although there were many uncontrollable variables that may have impacted some of the ratings received from the four participants, the use of a single-subject, multiple-baseline design allowed for flexibility and highlighted a number of potentially important considerations for clinical care and future research with this population. These four participants represent the 
larger population of adolescents who undergo spinal fusion surgery each year. Although these data cannot speak for the thousands of others as a cohesive group, it does represent the discomfort experienced following this surgery and the importance of working on interventions, such as the BodyPillow ${ }^{\circledR}$, to increase comfort and promote healing. 


\section{REFERENCES}

Abbott, F. V., Gray-Donald, K., Sewitch, M. J., Johnston, C. C., Edgar, L., \& Jeans, M. (1992). The prevalence of pain in hospitalized patients and resolution over six months. Pain, 50, $15-28$.

Advance Online Editions for Physical Therapists (January 5, 2004). Room to Grow. Retrieved February 7, 2006 from http://physical-therapy.advanceweb.com.

American Academy of Orthopaedic Surgeons (n.d.). Spinal Fusion. Retrieved July 19, 2006 from http://orthoinfo.aaos.org/fact/thr_report.cfm?Thread_ID=156\&topcategory=Spine

Apfelbaum, J. L., Chen, C., Mehta, S. S., \& Gan, T. J. (2003). Postoperative Pain Experience: Results from a national survey suggest postoperative pain continues to be undermanaged. Anesthesia and Analgesia, 97, 534-540.

Bianconi, M., Ferraro, L., Ricci, R., Zanoli, G., Antonelli, T., Giulia, B., Guberti, A., \& Massari, L. (2004). The pharmacokinetics and efficacy of ropivacaine continuous wound installation after spine fusion surgery, 98, 166-172.

Brain Waves (n.d.). Artificial may be better: trials begin for new disc. Retrieved February 7, 2006 from http://www.neuro.jhmi.edu/BrainWaves.

Blount, R. L., Piira, T., \& Cohen, L. L. (2003). Management of pediatric pain and distress due to medical procedures. In M. C. Roberts (Ed.). Handbook of pediatric psychology, $3^{\text {rd }}$ edition (pp. 216-233). New York: Guilford Press.

Corff, K.E., Seideman, R., Venkataraman, P.S., Lutes, L., \& Yates, B. (2006). Facilitated tucking: A nonpharmacologic comfort measure for pain in preterm neonates, Journal of Obstetric, Gynecologic, \& Neonatal Nursing, 24, 143-148.

DeMore, M., \& Cohen, L. L. (2005). Distraction for pediatric immunization pain: A critical 
review. Journal of Clinical Psychology in Medical Settings, 12, 281-291.

Dolin, S. J., Cashman, J. N., \& Bland, J. M. (2002). Effectiveness of acute postoperative pain management: I. Evidence from published data. British Journal of Anaesthesia, 89, 409423.

Filos, K. S., \& Lehmann, K. A. (1999). Current concepts and practice in postoperative pain management: Need or a change? European Surgical Research, 31, 97-107.

Fisher, W. W., Kelley, M. E., \& Lomas, J. E. (2003). Visual aids and structured criteria for improving visual inspection and interpretation of single-case designs. Journal of Applied Behavior Analysis, 36, 387-406.

Gallagher, E. J., Liebman, M., \& Bijur, P. E. (2001). Prospective validation of clinically important changes in pain severity measured on a visual analog scale. Annals of Emergency Medicine, 38, 633-638.

Good, M., Anderson, G. C., Ahn, S., Cong, X., \& Stanton-Hicks, M. (2005). Relaxation and music reduce pain following intestinal surgery. Research in Nursing \& Health, 28, 240251.

Halimaa S-L. (2003). Pain management in nursing procedures on premature babies. Journal of Advanced Nursing, 42, 587-597.

Halimaa S-L., Vehviläinen-Julkunene, K., \& Heinonen, K. (2001). Pain relieving measures for procedural pain in premature babies. An observational study, Vård i Norden, 21, 9-13.

Huang, N., Cunningham, F., Laurito, C. E., \& Chen, C. (2001). Can we do better with postoperative pain management? The American Journal of Surgery, 182, 440-448.

Kazdin, A. E. (1998). Research design in clinical psychology. Needham Heights, MA: Allyn \& Bacon. 
Kazdin, A. E. (1982). Single-case research designs: Methods for clinical and applied settings. New York: Oxford University Press.

Kleiber, C. \& Harper, D. C. (1999). Effects of distraction on children’s pain and distress during medical procedures: A meta-analysis. Nursing Research, 48, 44-49.

Mayo Clinic Medical Services (n.d.). Scoliosis. Retrieved January 23, 2006 from http://www.mayclinic.com/health/scoliosis/DS00194/DSECTION=8

McGrath, P. (1990). Pain in children: Nature, assessment, and treatment. New York: Guilford.

McGrath, P. J. \& Finley, G. A. (2003). Pediatric pain: Biological and social context. Seattle: International Association for the Study of Pain.

Melhuish, S. \& Payne, H. (2006). Nurses' attitudes to pain management during routine venepunture in young children, 18, 20-23.

Mohanty, S. P., Kumar, M. N., Kishore, B. N., \& Babu, S. S. (2001). The timing of spinal fusion in adolescent idiopathic scoliosis. Journal of Orthopaedic Surgery, 9, 7-14.

National Center for Health Statistics, Centers for Disease Control and Prevention (May 4, 2006). 2004 National Hospital Discharge Survey. Retrieved July 19, 2006 from http://www.cdc.gov/nchs/about/major/hdasd/listpubs.htm

North American Spine Society (n.d.). Spinal Fusion Surgery - What is it? How is it done? What is Spinal Fusion? Retrieved January 23, 2006 from http://www.spine.org/articles/spinalfusion.cfm

Parsonson, B. S., \& Baer, D. M. (1986). The graphic analysis of data. In A. Poling \& R. W. Fuqua (Eds.), Research methods in applied behavior analysis: Issues and advances (pp. 157-186). New York: Plenum Press. 
Piira, T., Hayes, B., \& Goodenough, B. (2002). Distraction methods in the management of children's pain: An approach based on evidence or intuition? The Suffering Child, 1.

Powers, S. W. (1999). Empirically supported treatments in pediatric psychology: Procedurerelated pain. Journal of Pediatric Psychology, 24, 131-145.

Salisbury, M. H., LaMontagne, L. L., Hepworth, J. T., \& Cohen, F. (2007). Parents’ selfidentified stressors and coping strategies during adolescents’ spinal surgery experiences. Clinical Nursing Research, 16, 212-230.

Shin, D., Kim, S., Kim, C. S., \& Kim, H. (2001). Postoperative pain management using intravenous patient-controlled analgesia for pediatric patients. The Journal of Craniofacial Surgery, 12, 129-133.

Sweet, S. D., \& McGrath, P. J. (1998). Physiological Measures of Pain. In Finley, G. A. \& McGrath, P. J. (Eds.), Measurement of pain in infants and children (pp. 59-81). Seattle: IASP Press.

Varni, J. W. Walco, G. A., \& Wilcox, K. T. (1990). Cognitive-biobehavioral assessment and treatment of pediatric pain. In A. M. Gross \& R. S. Drabman (Eds.), Handbook of clinical behavioral pediatrics, pp. 83-97. New York: Plenum Press.

Walch, J. M., Rabin, B. S., Day, R., Williams, J. N., Choi, K., \& Kang, J. D. (2005). The effect of sunlight on post-operative analgesic medication use: A prospective study of patients undergoing spinal surgery. Psychosomatic Medicine, 67, 156-163.

White, C. L., Pokrupa, R. P., \& Hoa Chan, M. (1998). An evaluation of the effectiveness of patient-controlled analgesia after spinal surgery. Journal of Neuroscience Nursing, 30, 225-232. 
White, O. R. (1974). The split middle: A quickie method of trend estimation. Seattle, WA:

University of Washington, Experimental Education Unit, Child Development and Mental Retardation Center. 


\section{APPENDIX A: FAMILY INFORMATION FORM}

Family Information Form

Please take a moment to complete the following forms. If you have any questions, please ask. Thanks!

1. Your Relation to Child: __ Mother __ Father __ Grandparent

If other, describe:

2. Your Gender: __ Male __ Female

3. Your Date of Birth: 1

4. Your Ethnicity: ___ Hispanic or Latino __ Not Hispanic or Latino

5. Your Race: __ White __ American Indian or Alaska Native __ Asian __Black or African American __ Native Hawaiian or Other Pacific Islander

6. The highest education level you completed (Please write a number. For example, 8 = completed middle school, $10=$ completed sophomore year of high school, $12=$ graduated high school, $13=$ completed freshman year of college, 16 = graduated college):

7. Your Marital Status: __ Single __ Married __ Separated __ Divorced
Widowed

If other, describe:

8. The highest education level your partner completed (Please write a number. For example, $10=$ completed sophomore year of high school, $12=$ graduated high school, 13 = completed freshman year of college, 16 = graduated college):

9. Approximate total family income per year

10. Child's Gender: ___Male __Female

11. Child's Date of Birth:

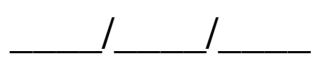

12. Child's Ethnicity: ___ Hispanic or Latino ___ Not Hispanic or Latino

13. Child's Race: _White __ American Indian or Alaska Native _Asian Black or African American __ Native Hawaiian or Other Pacific Islander 
14. How many other children live in the home? What are their ages?

15. How many other adults live in the home? What are their ages?

16. What chronic illness or medical condition led to your child's surgery?

How old was your child when he/she was first diagnosed with this condition?

17. Does this child have any other chronic illness or medical condition? $\mathrm{Y} / \mathrm{N}$ If so, What?

18. Please provide your mailing address and phone number (please print). Name:

Address:

Phone: 


\section{APPENDIX B: COMFORT RATING SCALE \\ Comfort Rating Scale}

Please answer the following question using the line below. Please remember to put a mark on the line so that it intersects. If you have any questions, feel free to ask.

1. How comfortable are you now?

Very Uncomfortable $\longrightarrow$ Very Comfortable 


\section{APPENDIX C: NURSE REPOSITIONING RECORD}

\section{Nurse's Repositioning Record}

Please fill out whenever you enter the room to (a) reposition the child or (b) to respond to complaint of discomfort

Nurse Initials:

\begin{tabular}{|c|c|c|c|c|c|}
\hline Time & Nurse & $\begin{array}{l}\text { Did Patient/Parent } \\
\text { Call Nurse? }\end{array}$ & $\begin{array}{l}\text { Current } \\
\text { Pillows? }\end{array}$ & $\begin{array}{l}\text { Change } \\
\text { Pillow? }\end{array}$ & Result of Interaction \\
\hline \multirow[t]{19}{*}{ ex: 8:12am } & Sarah P. & (y) or $n$ & body or hospital & $y$ or $n$ & repositioned pillows \\
\hline & & $\mathrm{y}$ or $\mathrm{n}$ & body or hospital & $\mathrm{y}$ or $\mathrm{n}$ & \\
\hline & & $\mathrm{y}$ or $\mathrm{n}$ & body or hospital & $\mathrm{y}$ or $\mathrm{n}$ & \\
\hline & & $\mathrm{y}$ or $\mathrm{n}$ & body or hospital & $\mathrm{y}$ or $\mathrm{n}$ & \\
\hline & & $\mathrm{y}$ or $\mathrm{n}$ & body or hospital & $\mathrm{y}$ or $\mathrm{n}$ & \\
\hline & & $\mathrm{y}$ or $\mathrm{n}$ & body or hospital & $\mathrm{y}$ or $\mathrm{n}$ & \\
\hline & & $\mathrm{y}$ or $\mathrm{n}$ & body or hospital & $y$ or $n$ & \\
\hline & & $\mathrm{y}$ or $\mathrm{n}$ & body or hospital & $\mathrm{y}$ or $\mathrm{n}$ & \\
\hline & & $\mathrm{y}$ or $\mathrm{n}$ & body or hospital & $\mathrm{y}$ or $\mathrm{n}$ & \\
\hline & & $\mathrm{y}$ or $\mathrm{n}$ & body or hospital & $\mathrm{y}$ or $\mathrm{n}$ & \\
\hline & & $\mathrm{y}$ or $\mathrm{n}$ & body or hospital & $\mathrm{y}$ or $\mathrm{n}$ & \\
\hline & & $\mathrm{y}$ or $\mathrm{n}$ & body or hospital & $\mathrm{y}$ or $\mathrm{n}$ & \\
\hline & & $\mathrm{y}$ or $\mathrm{n}$ & body or hospital & $\mathrm{y}$ or $\mathrm{n}$ & \\
\hline & & $\mathrm{y}$ or $\mathrm{n}$ & body or hospital & $\mathrm{y}$ or $\mathrm{n}$ & \\
\hline & & $\mathrm{y}$ or $\mathrm{n}$ & body or hospital & $\mathrm{y}$ or $\mathrm{n}$ & \\
\hline & & $\mathrm{y}$ or $\mathrm{n}$ & body or hospital & $\mathrm{y}$ or $\mathrm{n}$ & \\
\hline & & $\mathrm{y}$ or $\mathrm{n}$ & body or hospital & $y$ or $n$ & \\
\hline & & $\mathrm{y}$ or $\mathrm{n}$ & body or hospital & $\mathrm{y}$ or $\mathrm{n}$ & \\
\hline & & $\mathrm{y}$ or $\mathrm{n}$ & body or hospital & $\mathrm{y}$ or $\mathrm{n}$ & \\
\hline
\end{tabular}

Date:

Patient ID: 


\section{APPENDIX D: PAIN RATING SCALE}

\section{Pain Rating Scale}

Please answer the following question using the line below. Please remember to put a mark on the line so that it intersects. If you have any questions, feel free to ask.

1. How much pain are you in now?

No pain

Extreme Pain 
APPENDIX E: PATIENT SATISFACTION SCALE

Patient Satisfaction Scale

Please answer the following question using the line below. Please remember to put a mark on the line so that it intersects. If you have any questions, feel free to ask.

1. How satisfied were you with the hospital pillows?

Very Unsatisfied

Very Satisfied

2. How satisfied were you with the BodyPillows ${ }^{\circledR}$ ?

Very Unsatisfied

Very Satisfied

Please feel free to provide additional comments: 


\section{APPENDIX F: NURSE SATISFACTION SCALE \\ Nurse Satisfaction Scale}

Please answer the following question using the line below. Please remember to put a mark on the line so that it intersects. If you have any questions, feel free to ask.

1. How efficient were the hospital pillows?

Very Inefficient

Very Efficient

2. How efficient were the BodyPillows ${ }^{\circledR}$ ?

Very Inefficient

Very Efficient

3. What was the child's level of comfort with the hospital pillows?

Very Uncomfortable

Very Comfortable

4. What was the child's level of comfort with the BodyPillows ${ }^{\circledR}$ ?

Very Uncomfortable

Very Comfortable

Please feel free to provide additional comments regarding the BodyPillows ${ }^{\circledR}$ : 


\title{
APPENDIX G: RESEARCH ASSISTANT COMFORT, PAIN, AND HEART RATE RECORD
}

\author{
SHEET
}

Research Assistant Heart Rate, Pain, and Comfort Record

Participant ID:

Date:

RA:

\begin{tabular}{|c|c|c|c|c|c|}
\hline Time & Currer & nt Pillows & Comfort Rating & Pain Rating & Heart Rate \\
\hline 8:00 AM & body & or normal & & & \\
\hline $8: 10$ AM & body & or normal & $\varnothing$ & $\varnothing$ & \\
\hline $8: 20$ AM & body & or normal & & & \\
\hline $8: 30$ AM & body & or normal & $\varnothing$ & $\varnothing$ & \\
\hline $8: 40$ AM & body & or normal & & & \\
\hline $8: 50$ AM & body & or normal & $\varnothing$ & $\varnothing$ & \\
\hline 9:00 AM & body & normal & & & \\
\hline 9:10 AM & body & or normal & $\varnothing$ & $\varnothing$ & \\
\hline 9:20 AM & body & or normal & & & \\
\hline 9:30 AM & body & or normal & $\varnothing$ & $\varnothing$ & \\
\hline 9:40 AM & body & or normal & & & \\
\hline 9:50 AM & body & or normal & $\varnothing$ & $\varnothing$ & \\
\hline 10:00 AM & body & normal & & & \\
\hline $10: 10 \mathrm{AM}$ & body & or normal & $\varnothing$ & $\varnothing$ & \\
\hline 10:20 AM & body & or normal & & & \\
\hline 10:30 AM & body & or normal & $\varnothing$ & $\varnothing$ & \\
\hline 10:40 AM & body & or normal & & & \\
\hline 10:50 AM & body & or normal & $\varnothing$ & $\varnothing$ & \\
\hline 11:00 AM & body & or normal & & & \\
\hline 11:10 AM & body & or normal & $\varnothing$ & $\varnothing$ & \\
\hline 11:20 AM & body & or normal & & & \\
\hline $11: 30 \mathrm{AM}$ & body & or normal & $\varnothing$ & $\varnothing$ & \\
\hline 11:40 AM & body & or normal & & & \\
\hline $11: 50 \mathrm{AM}$ & body & or normal & $\varnothing$ & $\varnothing$ & \\
\hline 12:00 PM & body & or normal & & & \\
\hline 12:10 PM & body & or normal & $\varnothing$ & $\varnothing$ & \\
\hline 12:20 PM & body & or normal & & & \\
\hline 12:30 PM & body & or normal & $\varnothing$ & $\varnothing$ & \\
\hline 12:40 PM & body & or normal & & & \\
\hline 12:50 PM & body & normal & $\varnothing$ & $\varnothing$ & \\
\hline
\end{tabular}

